Abstract M141 Table 1 Change in peak CPET variables and inspiratory capacity at isotime with and without beta-blockade in 46 subjects with and without COPD

\begin{tabular}{|c|c|c|c|c|}
\hline \multirow[b]{2}{*}{$\beta$-blocker } & \multicolumn{2}{|c|}{ COPD $(n=25)$} & \multicolumn{2}{|c|}{ No $\operatorname{COPD}(n=21)$} \\
\hline & ON & OFF & ON & OFF \\
\hline & 17.4 & 17.8 & 19 & 18.9 \\
\hline \multirow[t]{2}{*}{ Peak V02 } & (3.5) & (3.5) & $(6.1)$ & (6.3) \\
\hline & 1.43 & 1.46 & 1.58 & 1.56 \\
\hline \multirow[t]{2}{*}{ Peak V02/kg } & $(0.31)$ & $(0.32)$ & $(0.51)$ & $(0.47)$ \\
\hline & 102\# & 106 & 113 & 110 \\
\hline \multirow[t]{2}{*}{ Peak Work } & (27) & (27) & (30) & (31) \\
\hline & $37.2 \#$ & 38.7 & 39.2 & 39.3 \\
\hline \multirow[t]{2}{*}{ Peak VE/VO2 } & $(4.9)$ & (5.7) & $(5.3)$ & $(5.1)$ \\
\hline & 33.9 & 34.6 & 34.6 & 35.3 \\
\hline \multirow[t]{2}{*}{ Peak VE/VCO2 } & (3.3) & (3.9) & (3.9) & (3.8) \\
\hline & $12.6 \# \#$ & 10.9 & 14 \#\# & 11.9 \\
\hline \multirow[t]{2}{*}{ Peak 02 Pulse } & $(2.6)$ & (2.4) & $(3.7)$ & (3.1) \\
\hline & 114 \#\# & 134 & 114 \#\# & 132 \\
\hline Peak HR & (15) & (17) & (25) & (19) \\
\hline$\Delta \mathrm{IC}$ isotime (ml) & $-142 \sim$ & $-188 \sim$ & -15 & -16 \\
\hline
\end{tabular}

the impact of beta-blockade in people under abdominal aortic aneurysm surveillance we examined the impact of beta-blockade on CPET variables and dynamic hyperinflation at peak exercise

55 subjects were recruited though only 46 completed incremental CPET off and on beta-blockers. Mean age was 70 (6) years and $42(91 \%)$ were male. IHD or heart failure was diagnosed in 13 people and COPD diagnosed in 7. However, 24/46 (52\%) had post-bronchodilator airflow obstruction consistent with COPD (10 mild, 10 moderate and 4 severe). 18 were routinely prescribed beta-blockers (mainly bisoprolol). Those taking beta-blockers stopped treatment for the second CPET and other subjects commenced weight-adjusted bisoprolol before the second CPET.

The 25 COPD subjects had a mean $\mathrm{FEV}_{1}$ of 2.14 (0.62) L, FEV predicted $76(20) \%$ and $\mathrm{FEV}_{1} / \mathrm{FVC} 0.54$ (0.11). The main results are shown in the table. Compared with the subjects without COPD at peak exercise the COPD subjects had slightly lower VO2, work and ventilatory equivalents but these did not differ significantly. When beta-blocked both COPD and non-COPD subjects had a lower heart rate $(\mathrm{p}<0.001)$ and consequently oxygen pulse $(\mathrm{p}<0.001)$ but there was a minimal effect on other variables. The COPD patients showed a greater fall in IC $(\mathrm{p}=0.02)$ but the addition of a beta-blocker did not have any additional effect. The 7 subjects already diagnosed with COPD did not differ from the whole COPD group.

In an unselected clinic population with arterial vascular disease a majority of people had, mostly undiagnosed, COPD albeit predominantly mild to moderate. Continuation or commencement of beta-blockers had little effect on level of peak exercise or degree of dynamic hyperinflation. This supports the use of beta-blockers in this COPD population, both in a peri-operative setting and for a cardiac indication.

\section{M142 THE ASSOCIATION BETWEEN EXACERBATION FREQUENCY AND STROKE RISK, IN PATIENTS WITH COPD: A MATCHED CASE-CONTROL STUDY}

CL Windsor, E Herrett, L Smeeth, I Quint. London School of Hygeine and Tropical Medicine, London, UK

10.1136/thoraxjnl-2014-206260.437
Introduction and objectives COPD patients have been shown to have a higher incidence of MI and stroke, than the general. ${ }^{1}$ There is also evidence that the risk of MI and stroke, in COPD patients, increases following an exacerbation. ${ }^{2}$ However, the association appears stronger between COPD exacerbations and MI, than it does between COPD exacerbations and stroke. ${ }^{1,2} \mathrm{We}$ hypothesise that COPD patients, who are frequent exacerbators, have a higher stroke risk, than those who are infrequent exacerbators, even when stable.

Methods COPD patients, with a first stroke between 2004 and 2013, were identified in the UK CPRD database, as cases. Controls, were COPD patients, registered in the CPRD database, matched $3: 1$, to cases on age, sex and GP practice. We defined "frequent exacerbators" as COPD patients, with $\geq 2$ exacerbations, resulting in treatment, per year and "infrequent exacerbators" as $\leq 1$ exacerbation, per year. We also grouped exposure into four levels; $0,1,2$ or $\geq 3$ exacerbations, per year, to allow an analysis for trend between exacerbation number and stroke. A subgroup analysis of the association between exacerbation frequency and stroke type (ischaemic/ haemorrhagic or TIA) was also carried out. Conditional logistic regression was used for the analyses.

Results There were 6,441 cases and 19,323 controls. No difference was found in odds of stroke, comparing frequent and infrequent exacerbators (adjusted ${ }^{\ddagger}$ OR $0.95,95 \%$ CI $0.89-1.01, \mathrm{p}=$ 0.09 ), or in the odds for stroke of any type. However, there was a reduction in odds of stroke associated with increased number of exacerbations, per year, with evidence for a linear trend $(\mathrm{p}=$ 0.002) (see Table 1.)

Conclusion These findings do not support the hypothesis that exacerbations in COPD are associated with increased stroke risk and warrant further investigation.

$\ddagger$ Adjusted for age, sex, general practice, smoking status, family history, hypertension, heart failure, CABG, angina, B-blocker and Calcium channel blocker.

\section{REFERENCES}

1 Feary, JR, et al. Prevalence of major comorbidities in subjects with COPD and incidence of myocardial infarction and stroke: a comprehensive analysis using data from primary care. Thorax, 2010;65(11):p. 956-62

2 Donaldson, GC, et al. Increased risk of myocardial infarction and stroke following exacerbation of COPD. Chest, 2010:137(5): p. 1091-7

\section{M143 PROGRESSION OF CENTRAL ARTERIAL STIFFNESS IN COPD AFTER 2 YEARS OF OBSERVATION}

${ }^{1}$ NS Gale, ${ }^{1}$ AM Albarrati, ${ }^{1} \mathrm{MM}$ Munnery, ${ }^{1} \mathrm{IC}$ Munnery, ${ }^{2} \mathrm{RM}$ Tal-Singer, ${ }^{1} \mathrm{JR}$ Cockcroft, ${ }^{1} \mathrm{DJ}$ Shale. 'Wales Heart Research Institute, Cardiff University, Cardiff, UK; ${ }^{2}$ GlaxoSmithKline $R$ and D, King of Prussia, Pennsylvania, USA

\subsection{6/thoraxjnl-2014-206260.438}

Background COPD is a systemic disease with associated comorbidities including cardiovascular disease which have significant impact on morbidity and mortality. The heterogeneity of COPD has led to the concept of phenotypes; one of which may describe patients at greater cardiovascular risk. Aortic pulse wave velocity (aPWV) is a validated measure of arterial stiffness and an independent predictor of cardiovascular outcomes, and has been shown to be elevated in patients with COPD. ${ }^{1}$ We hypothesised that a subgroup of patients (progressors) would demonstrate increased aPWV over 2 years.

Methods The ARCADE study is a longitudinal study of cardiovascular risk and other comorbidities. Assessments include spirometry, BMI, aPWV and blood pressure, (BP), mean arterial 